\title{
La concentración de poder supone el silencio de la diversidad
}

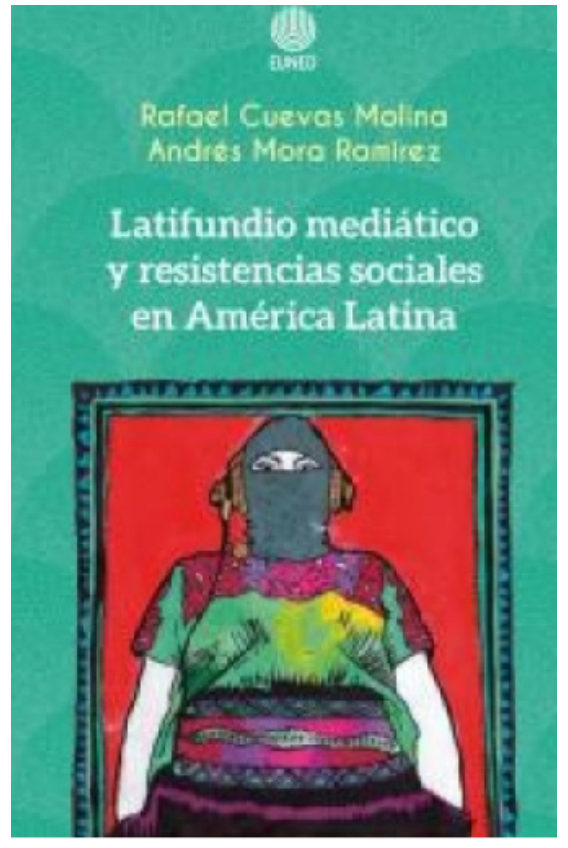

\section{Latifundio mediático y resistencias sociales en América Latina}

Rafael Cuevas Molina y Andrés Mora

Ramírez

Editorial Universitaria Estatal a Distancia, San José, Costa Rica, 2016

368 páginas

Reseña por Daniel Rodrigo-Cano

El libro del guatemalteco Rafael Cuevas Molina y del costariquense Andrés Mora Ramírez 'Latifundio mediático y resistencias sociales en América Latina', parte en una evolución histórica de los medios de comunicación y para ello parte de la llegada de la imprenta a América en 1539 como un intento de transmitir información institucional y religiosa. Más allá de la misión informativa, los medios de comunicación no son solo transmisores sino que también son gestores de sentimientos y formadores de opinión, por lo que se han ido convirtiendo en el centro de intereses político, ideológicos y comerciales. Es decir que los medios de comunicación son enormes maquinarias patriarcales, lucrativas y de poder.

Esta obra se divide en siete capítulos, en los que tras una introducción en la que se realiza un recorrido histórico de los medios de comunicación en latinoamérica se centra en los casos más relevantes de concentración de medios en diferentes países americanos como Argentina, Brasil, Venezuela o Ecuador.

El texto avanza hasta centrarse en algunos casos específicos como la cadena de televisión multiestatal latinoamericana TeleSur que desde 2005 replantea la construcción de un nuevo

\footnotetext{
Forma de citar:
}

Rodrigo-Cano, D. (2019). La concentración de poder supone el silencio de la diversidad. Ámbitos. Revista Internacional de Comunicación 43(1), 160-162. doi: 10.12795/Ambitos.2019.i43.08 
orden internacional de la comunicación alejada de la tradicional macdolización cultural que impone el neoliberalismo y la concentración de medios en unas pocas manos y que impide el desarrollo de la diversidad cultural. Otro caso es el del modelo de comunicación alternativa del Ejército Zapatista de Liberación Nacional del movimiento indígena de Chiapas, en el que se trata de devolver el habla al pueblo, como propone Mattelart, y que este movimiento aprovecha los espacios abiertos por las redes sociales para desarrollar un guerrilla de la web (netwar) de forma similar a otros movimientos como el 15M, la Primavera Árabe, Occupy Wall Street u otras más recientes que han ido recorriendo todo el planeta, como movimientos en Hong Kong, Chile, en México (\#Yosoy132) o en Francia (\#NuitDebout).

En contraposición los autores dedican el penúltimo capítulo al amarillismo y el sensacionalismo de la espectacularidad de los medios transnacionales como Cable News Networks (CNN) o Univisión y Telemundo. Estos medios son principales exponentes, para éstos autores, de la mundialización de la información asociada al capitalismo y, por tanto, polarizante. La concentración informativa que poseen estos medios estrechan la pluralidad generando un pensamiento único al convertirse en fabricantes de consenso y auténticos partidos políticos que, en ocasiones se alinean con el poder como por ejemplo es el grupo norteamericano y mediático Sinclair, cercano al presidente Trump.

Los autores finalizan su obra con un capítulo dedicado a lo que denomina derecho al picaporte, que lo definen como el derecho a obtener información en cualquier lugar y en cualquier momento llamando a la puerta que sea necesaria lo que pone en cuestión la independencia periodística y que ha llevado a la actual deslegitimación de la profesión de periodismo. Finalmente se recogen ejemplos de concentración mediática en países centroamericanos: Guatemala, Honduras, El Salvador, Nicaragua, Costa Rica y Panamá.

El libro escrito por Cuevas y Mora, se trata de un recorrido histórico y hasta la actualidad de la realidad mediática en Latinoamérica, y por comparación con realidad de concentración de medios en todo el mundo con, la más que probable, disminución de la diversidad cultural y poder económico y social para derrocar o imponer gobiernos. Además, la lectura del mismo permite un recorrido por los principales autores de la educación latinoamericana como Mattelart, Martín Barbero, Tremont, García Canclini, Paolo Freire, Amin, Castells...

Esta publicación está en la línea de la publicación de Ramón Reig y Aurora Labio: "El laberinto mundial de la información" en el que en un recorrido editorial Anthropos/Siglo XXI y que escasean en las publicaciones científicas. La publicación de los profesores Reig y Labio participan varios autores de diferentes universidades y recoge el panorama de la información a escala mundial, 
y por tanto también en Latinoamérica, en un capítulo sobre la concentración mediática y los cambios en la regulación del sector escrito por la profesora Rosalba Mancinas. Ambos textos se complementan a la perfección para entender que son pocas las voces que dominan el espectro mediático mundial y que silencian la diversidad real y social del siglo XXI. 